\title{
Libertad de cultos o tolerancia religiosa: anticlericalismo en el Perú (1900-1915)
}

\section{Religious freedom or religious tolerance: anticlericalism in Peru 1900-1915}

\author{
Robert Salazar Quispe ${ }^{1}$ \\ Universidad Nacional Federico Villarreal, Universidad Nacional Mayor de San Marcos, \\ Universidad Nacional Tecnológica de Lima Sur. Lima, Perú \\ rsalazar@unfv.edu.pe/ rsalazar@untels.edu.pe
}

\section{RESUMEN}

La libertad de cultos, objeto de controversia a inicios del siglo $\mathrm{XX}$, fue una conquista que liberales y evangélicos consiguieron el 11 de noviembre de 1915 ante el Congreso de la República del Perú. Sin embargo, este proceso se fue gestando en toda la época republicana, desde que los protestantes y evangélicos empezaron a tener presencia significativa en el Perú. El avivamiento protestante del siglo XVII en Norteamérica fue el detonante principal para el inicio del proyecto misionero y de labor espiritual en América. Para el caso del Perú, esta labor se inicia en 1822, con la presencia del misionero Diego Thomson. El proceso del establecimiento de evangélicos y protestantes continuó durante todo el siglo XIX y la prédica del pensamiento anticlerical latinoamericano se fue expresando paulatinamente en varias regiones del Perú, hasta lograr tener seguidores que buscaban la igualdad frente a la presencia casi total de los católicos. La libertad de cultos se convirtió así en un objetivo central del pensamiento liberal de inicios del siglo XX y transformó la mentalidad recalcitrante católica en aras de permitir la prédica evangélica en todo el territorio peruano.

1 Docente universitario adscrito al Departamento de Humanidades de la Universidad Nacional Federico Villarreal, la Escuela de Estudios Generales de la Universidad Nacional Mayor de San Marcos y la Universidad Nacional Tecnológica de Lima Sur. Historiador, especialista en el proceso histórico cultural del Perú del siglo XX, enfocado en la historia local y regional, así como en los procesos de desarrollo y crecimiento de los distritos limeños, mediante el proceso de migraciones. Magíster en Docencia Universitaria con mención en Investigación. Ha investigado sobre el aprendizaje autónomo y su relación con las tecnologías de la información y comunicación (TIC). Actualmente desarrolla el proyecto de la «Historia de América Latina», mediante la Revista del Siglo, donde se analiza el proceso histórico-social de América Latina durante el siglo XX. 


\section{PALABRAS CLAVE}

Libertad de cultos, tolerancia religiosa, anticlericalismo, protestantes y evangélicos, liberales, misioneros

\section{ABSTRACT}

Religious freedom, still the subject of controversy at the beginning of the 20th century, was a victory extracted by liberals and evangelicals from the Congress of the Republic of Peru on November 11th 1915; however, the process had begun during the early years of the republic, as the presence of protestants and evangelicals began to grow. The protestant revival of the 17th century in North America was the main catalyst for the launch of a missionary project and spiritual work in the Americas; in the case of Peru, such work began in 1822, with the arrival of the missionary Diego Thomson. The establishment of evangelical and protestant communities continued throughout the 19th century, and the preaching of Latin American anticlerical thought spread gradually throughout several regions of Peru, gaining a following who sought equality with the overwhelming presence of the "Catholics». It was in this context that religious freedom became a central tenet of liberal thought during the first years of the 20th century, leading to a transformation in hardline Catholic thinking and the permitting of evangelical teaching throughout Peruvian territory.

\section{KEYWORDS}

Religious freedom, religious tolerance, anticlericalism, protestants and evangelicals, liberals, missionaries

\section{Introducción}

¡Nacimos indios, esclavos del cura, esclavos del gobernador, esclavos del cacique, esclavos de todos los que agarran la vara del mandón!

Clorinda Mattos de Turner, Aves sin nido

En 2015, se celebró en el Perú el centenario de la libertad de cultos, que significó una conquista de liberales y evangélicos, quienes buscaron desde diversas posiciones cambiar la legislación estatal para permitir la tolerancia religiosa. De esta manera, el 11 de noviembre de 1915 el Congreso de la República acordó modificar el artículo 4 de la Constitución, que reconocía a la Iglesia católica como religión del Estado y que prohibía el ejercicio público de cualquier otra religión. Mediante este artículo se 
suprimió la frase "y no se permite el ejercicio público de alguna otra» y quedó establecida la libertad de cultos en el Perú. Esta conquista fue producto de una larga historia anterior. Veamos sus fases y etapas.

\section{La etapa de los precursores evangélicos (1824-1891)}

La presencia evangélica en el Perú a inicios de la República responde a dos procesos que ocurrieron en el mundo occidental. En primer lugar, se relaciona con el avivamiento religioso protestante del siglo XVII en Estados Unidos e Inglaterra, y al fenómeno de la expansión del capitalismo europeo y británico en el siglo XIX y anglosajón y americano en el XX. Bajo estos aspectos, el primer momento de la presencia evangélica corresponde a la llegada de Diego Thomson al país en 1822.

Diego Thomson era un misionero bautista escocés que buscó introducir en el país el sistema de la educación lancasteriana² ${ }^{2}$ Llegó a petición de Bernardo Monteagudo y José de San Martín para organizar la educación pública. Thomson organizó escuelas mixtas de educación popular con el sistema lancasteriano en varios países del continente y el 19 de setiembre de 1822, en el local del colegio de Santo Tomás, estableció una escuela normal, donde se planteaba la estructura normalista.

No obstante, Thomson intentaba llevar a cabo un proyecto misionero mayor. Mostraba un trabajo de promoción humana basado en el servicio y la acción social, en el cual la separación entre trabajo «espiritual» y trabajo «material» no tenía la rigidez ni la tensión que tuvo en un periodo posterior en la historia de la Iglesia evangélica. De esta manera se coloca como el primer protestante que actuaba libremente en el país.

el primer protestante que actuó libremente en el Perú fue el escocés Diego Thomson. Este fue un personaje carismático que a pedido de San Martín llegó a Lima para implantar el sistema lancasteriano. Bolívar, convencido de que este era el «único método para promover pronta y eficazmente la instrucción pública» dio su pleno apoyo a Thomson en el establecimiento del sistema de Lancaster en el Perú. Aun cuando Thomson pudo actuar con libertad, sus actividades no estuvieron exentas del acoso del clero, pero él supo retirarse a tiempo del escenario y los que le sucedieron en la tarea protestante

2 El método lancasteriano es atribuido a José Lancaster (1799-1938). Consistía en la educación mutua y monitorial. Se escogía a los alumnos más avanzados para ser utilizados como monitores frente a otros alumnos. Se trataba de un sistema multiplicativo, de coste barato y que permitía una rápida alfabetización. Era la sensación en Inglaterra y los Gobiernos latinoamericanos, liberales, decidieron importarlo al Perú. La British \& School Society era la organización internacional encargada de difundirlo, de modo que envió a Thomson a Buenos Aires en 1818 para hacer tal labor. Como pastor bautista, la Iglesia de Edimburgo pagó los pasajes a Thomson, que una vez en América continuó siendo subvencionado por los Gobiernos de Argentina y Chile, en cuyo país estuvo de 1821 a 1822, antes de llegar al Perú. 
tuvieron que esperar décadas para tener cierta libertad real en el país (Alomía, 1998).

De modo paralelo con el trabajo de educación, Thomson llevó a cabo una gran labor misionera distribuyendo las Escrituras, primero como voluntario y luego como agente de la Sociedad Bíblica Británica (SBB), y extendiendo la evangelización en el Perú mediante la labor educativa, durante más de 30 años. Contó con el apoyo paulatino de otros misioneros como Juan Ritchie, quien señala que «Thomson no era primeramente pedagogo sino misionero» y su mensaje era la afirmación del cristianismo.

Continuando con la labor de Thomson, la SBB estableció un grupo denominado «Colportores de la Biblia» integrado por Lucas Matthews (1828) y A. J. Duffiel (1857), quienes intentaron continuar con el trabajo de colocación de Biblias y porciones del Nuevo Testamento. Este esfuerzo fue continuado por el misionero metodista William Taylor, quien Ilega al Perú en 1877 e intenta desarrollar una estrategia de evangelización y servicio social a través de la apertura de templos y escuelas para niños, tanto extranjeros como peruanos.

Las facilidades que tuvieron estos misioneros para la prédica protestante se enmarcó en las constantes diatribas en la legislación peruana y las pugnas existentes entre liberales y conservadores. Así, el primer proyecto de ley sobre religión en el Perú se presentó en el primer Congreso Constituyente (donde 26 congresistas de los 79 eran clérigos) y proponía el siguiente artículo: «La religión del Estado es la católica, apostólica y romana».

Si bien el artículo propuso la protección de la Iglesia católica, no mencionó la exclusividad del catolicismo y dejó la puerta abierta a la libertad de cultos, posición respaldada por el clero liberal. Sin embargo, esta postura inicial no prosperó y se organizó un movimiento entre católicos y conservadores que favoreció el cambio del texto del artículo con el agregado: «La religión de Estado es la católica, apostólica y romana, con exclusión de cualquier otra».

En este contexto la prédica anticlerical solo fue posible mediante la labor misionera anclada en la repartición de las Escrituras, pero la campaña contra el clero continuó hasta llegar a su momento cumbre en la Asamblea Constituyente de 1855-1856, cuando se eliminaron los diezmos y el fuero eclesiástico, lo que provocó el rechazo de muchos católicos y sirvió para legitimar la sublevación de Manuel Ignacio Prado en Arequipa en 1855. Sin embargo, debido a la posición fuertemente conservadora, en 1860, el presidente Ramón Castilla convocó un nuevo Congreso Constituyente encabezado por Bartolomé Herrera, donde se aprobó nuevamente 
la eliminación de los diezmos y el fuero eclesiástico y se ratificó a la Iglesia católica como la única protegida por el Estado.

En 1867 los liberales redactaron una Carta Magna. Ellos habían vuelto al poder bajo el mando del caudillo Mariano Ignacio Prado. Fernando Casós, diputado por Trujillo, pronunció un discurso a favor de la libertad de cultos, que fue seguido de una votación en la cual la prohibición contra el ejercicio público de otros cultos fue aprobada por 43 votos contra 41 . No obstante esta derrota, los liberales volvieron a la carga y en 1868 lograron su primera victoria mediante la autorización del Gobierno para la creación de cementerios laicos, donde no era necesario profesar una religión para estar enterrado.

En este ambiente se produjo un momento crucial en las misiones protestantes, el llamado caso Penzotti:

Penzotti era un emigrante italiano radicado en el Uruguay desde los 13 años de edad; se convirtió al protestantismo en 1875. Desde esa época, realizó una serie de trabajos para la Sociedad Bíblica Americana (SBA). Visitó el Perú varias veces con motivo de este trabajo de colportaje de las Escrituras. Algunos años después, la SBA le encargó formar una agencia para la distribución de la Biblia en el área andina. Es así que se establece en el Perú en 1888. Para ese entonces todos los trabajos misioneros protestantes anteriores habían cerrado. Penzotti comenzó un trabajo de venta de biblias y presentación del Evangelio, casa por casa y en lugares públicos. De esta manera logró formar un grupo de estudio bíblico y luego reunió suficiente gente para iniciar servicios evangélicos (Amat y Pérez, 2007).

Penzotti, quien profesaba la fe metodista, se dedicó a vender biblias y libros religiosos y a realizar actividades proselitistas en Lima y algunos departamentos como Ica, Áncash, Arequipa, Cusco, entre otros. Este trabajo del misionero produjo la primera congregación evangélica para peruanos establecida en nuestro país en 1888, con un número de asistentes contabilizados en 300 personas aproximadamente. Pero este trabajo fue arduo, como lo recuerda Penzotti en su autobiografía:

Por fin, en julio de 1888 , llegamos al Callao, donde fijamos nuestra residencia y sin pérdida de tiempo pusimos mano a la obra. Muy poco se había hecho con la Biblia y nunca se había predicado el Evangelio en el idioma del país. Mi primer cuidado fue el de buscar un local donde poder predicar a la gente y luego fui de puerta en puerta, con la Biblia, para leerles, explicársela e invitarlos a concurrir a los servicios. Mi primer auditorio consistió de dos personas, además de los míos: don Manuel Noriega y su esposa. Al domingo siguiente vinieron cuatro personas, el subsiguiente ya eran 10 , al otro subieron a 20 , luego 30 , después $40,50,60,80 .$. Ya no cabían más y se presentaba 
el problema de buscar un local más grande. No sin mucho trabajo logramos conseguirlo, pero en tal condición de pobreza que con nuestras propias manos no tuvimos que ponerle piso, cielo raso, luz, hacer bancos y demás muebles necesarios (Escobar, 1984).

En este contexto la Iglesia católica reaccionó e inició una persecución y hostigamiento contra Penzotti, intentando deslegitimar este esfuerzo misionero o simplemente obstaculizar su trabajo. Este hostigamiento empezó desde los púlpitos y continuó por medio de impresos y también con la utilización de imágenes en procesión, como lo menciona El Comercio: «Los fieles católicos del Callao crearon una imagen llamada el "Señor del Mar"y formaron una gran procesión y al pasar por delante de la casa de Penzotti gritaron: “`iva la religión católica, apostólica, romana!". Todos contestaron “¡Viva!”y luego añadían: ¡Muera Penzotti! ¡Afuera los protestantes!”, al mismo tiempo que arrojaban una gran lluvia de piedras».

Estas acciones motivaban el desarrollo de los cultos en estricto privado, con invitación y a puerta cerrada para evitar quebrantar el artículo cuarto de la Constitución de aquel entonces, que prohibía la celebración de cultos de otras religiones no católicas en público, pero que no decía nada de la celebración de servicios religiosos en privado. Penzotti continuó con la prédica cristiana y empezó a extenderla fuera de Lima al viajar a Arequipa, donde continúo leyendo la Biblia y explicando el papel de la salvación.

En Arequipa Penzotti sufrió su primer encarcelamiento por orden del obispo Huertas, quien lo acusaba de «introducir clandestinamente libros inmorales y corruptores». Sin embargo, estando en prisión el misionero continuó con la prédica a los presos. Diecinueve días después, a fines de 1889, salió en libertad a pedido del presidente Andrés A. Cáceres, quien tomó la decisión guiado por algunos amigos liberales y por el embajador italiano en el país. Luego de estos hechos regresó al Callao.

Poco tiempo después, el juez Porras expidió una orden de prisión contra Penzotti, acusándolo de haber violado el artículo 4 de la Constitución, que excluía todo culto público que no proviniera de la religión católica. Fue encerrado el 26 de julio de 1890 en la prisión Casas Matas del Callao, en la cual escribió con puño y letra en las paredes las siguientes frases:

¿Qué me importan del mundo las penas,

Y doblada tener la cerviz?

¿Qué me importa que esté entre cadenas,

Si me espera una patria feliz?

Resignado, tranquilo y dichoso,

De la aurora me encuentra la luz, 
Porque sé que Jesús bondadoso,

Por su pueblo ha expirado en la cruz.

Mientras Penzotti se mantenía en prisión, diariamente se libraban agitaciones y conflictos en la prensa. A su vez, nacían los esfuerzos de los liberales y las logias masónicas, y prosperaban las cartas y telegramas de Londres y Estados Unidos, que incitaban a realizar investigaciones para obtener la libertad de Penzotti. Finalmente, se le concedió la libertad en marzo de 1891, después de lo cual Penzotti continuó con la predicación hasta su partida a Buenos Aires. Dejó en su reemplazo al misionero metodista Thomas Wood.

Con el caso de Penzotti se consiguieron por lo menos los siguientes resultados:

1. Se demostró que era posible realizar cultos evangélicos en privado, sin violación de la ley.

2. Se facilitó el trabajo de los futuros colportores, al probar que la venta y distribución de las Escrituras no podía ser considerada como un delito.

3. Se generó un movimiento de opinión pública a favor de la libertad de Penzotti, lo cual logró granjear la simpatía de varios sectores del pueblo hacia el protestantismo.

\section{Sectores en pugna: 1891-1907}

Sin duda que la prédica de Penzotti removió el ambiente político, social y religioso del país, al tiempo que el misionero Thomas Wood continuaba con la lucha por las reivindicaciones anticlericales en el Perú. Bajo su influencia y gestión se consiguieron algunas libertades más en materia de derechos ciudadanos, como fue el caso del matrimonio civil para las personas que no pertenecían a la Iglesia católica (1891).

Esta prédica no era ajena al pensamiento anticlerical que se expresaba ya en Latinoamérica. Por ejemplo, el 23 de agosto de 1890 se publicó el relato del escritor brasileño Henrique Coelho Netto, Ilamado «Magdala», en el que se describía la supuesta atracción de Jesús por la pecadora arrepentida María Magdalena. El cuento fue considerado sacrílego y el propio arzobispo de Lima, Manuel Antonio Bandini, prohibió a los católicos, bajo pena de pecado mortal, la lectura, venta y difusión de El Perú llustradoº,

3 El 1 de octubre de 1889, Clorinda Matto de Turner fue nombrada directora de redacción de El Perú llustrado, que se encontraba bajo la dirección general de Peter Bacigalupi desde su fundación en 1887. Durante el periodo en el que Matto de Turner asumió la dirección (18891891) de este importante órgano de difusión, se fomentó el americanismo literario invitando a escritores nacionales y latinoamericanos para que expusieran sus diferentes puntos de vista. Además, se promovieron las publicaciones de las escritoras. En este contexto, Matto de Turner siguió luchando por la incorporación de la cultura andina y la mujer a la nación. En 
donde se publicó la obra. El semanario era dirigido por Clorinda Matto de Turner.

Clorinda fue acusada de tener una posición anticlerical desde la difusión de Aves sin nido, novela en que se denunciaba la ruindad del clero provinciano ${ }^{4}$, manifestaba que la Iglesia tendría que limitarse a satisfacer las necesidades espirituales de sus fieles y que los sacerdotes deberían tener la posibilidad de casarse, para así servir a un cristianismo puro. Consideraba que el matrimonio permitiría a los sacerdotes encauzar su sexualidad por una salida natural y además les permitiría contar con los sabios consejos de una mujer. Esto conllevó a que la Unión Católica organizara un mitin de protesta contra esta actividad. El 11 de julio de 1891, Clorinda fue excomulgada. El Gobierno del general Andrés Avelino Cáceres cerró su imprenta y la escritora fugó a Argentina, donde abrazó de lleno el credo protestante, en su versión evangélica.

Con la instauración de grupos protestantes en el Perú se urdió también una férrea resistencia de la curia y sectores católicos. La Iglesia tomó conciencia de la necesidad de hacer frente a estos embates y con la ayuda de los jesuitas ${ }^{5}$ y reforzó sus tareas educativas mediante la Unión Católica, compuesta de varones y damas. La Unión Católica es la respuesta orgánica de la Iglesia, apoyándose en el naciente movimiento laico, para contrarrestar las embestidas de los grupos radicales. La Iglesia buscó reforzar desde dentro la Democracia Cristiana y en este pensamiento participaron monseñor Manuel Tovar y monseñor Carlos García Irigoyen, quien fue el primer director de la publicación oficial del Arzobispado de Lima, El Amigo del Clero.

El Amigo del Clero era un boletín oficial del Arzobispado de Lima y como tal se proponía ser un espacio de difusión de las actividades

estos años, publicó su renombrada novela Aves sin nido (1889), Bocetos al lápiz de americanos célebres (1890) y escribió un vasto número de ensayos, tradiciones y leyendas en los que resaltan las preocupaciones de su producción global.

4 Aves sin nido relata la historia de Lucía Marín, joven de buena familia, que, junto con su marido, un ingeniero metalúrgico, se establece en Killac, pueblecillo andino. Lucía, extranjera, se ve horrorizada ante la corrupción que observa en Killac, donde el gobernador y el sacerdote del pueblo consienten gran explotación contra los indígenas. Figura aquí una descripción de las instituciones que esclavizan y empobrecen a los indios, así como una serie de ejemplos del abuso de poder. Una de estas instituciones es la Iglesia católica dirigida por el sacerdote, don Pascual, quien se preocupa exclusivamente por su bienestar físico, su avaricia, su debilidad, su sensualidad desbordada y sus negativas a prestar ayuda a los necesitados con objetos de constantes críticas.

5 A pesar de que la ley del 26 de noviembre de 1855 prohibía el establecimiento en el Perú de la Compañía de Jesús, a partir de 1886 se produjo una serie de debates por la llegada de la Compañía, que desencadenó que los padres jesuitas se establecieran en Huánuco e iniciaran nuevamente una labor evangelizadora, contando con el apoyo del Gobierno. 
de la Iglesia, en una perspectiva universal, nacional y local. También se proponía llegar a la feligresía educándola, por medio de temas de interés familiar y personal, descubriendo lo simple y sencillo que son los grandes temas teológicos y pastorales, puestos al alcance del gran público, para ayudarles en la vida diaria (Armas, 1998).

En su estructura, El Amigo del Clero se componía de un editorial muy breve, que trataba normalmente sobre los tiempos del calendario de culto o algún hecho de importancia social nacional; continuaba una serie de secciones estables: «Noticias varias», «Sección oficial», «Documentos pontificios», "Preguntas y respuestas», «Miscelánea» y otras secciones variables de enseñanza litúrgica y homilética. El boletín pronto contó con un número aceptable de suscriptores en Lima y provincias, además de lectores ocasionales, de modo que su nivel de influencia en la feligresía fue muy fuerte desde los inicios.

A pesar de este embate del catolicismo, los sectores liberales lograron que en 1896 se aprobara el derecho al matrimonio civil para los no católicos. Con este decreto, la hija de Tomas Wood, fundador de la Iglesia metodista en el Perú, se casó e inscribió su matrimonio en el registro. A partir de entonces los no católicos tenían el derecho de inscribir formalmente sus matrimonios ante los agentes consulares o ante los ministros de cultos. Esta legislación se vio reforzada con la ley de 23 de noviembre de 1903, según la cual era suficiente que cualquiera de los contrayentes declarase no pertenecer a la comunión católica o haberse separado de ella.

Junto a este suceso un hecho llama la atención, la conversión del sargento mayor del Ejército peruano Teodomiro Rodríguez Cuevas, Rumi Maqui, quien en 1915 encabezó una corta pero resonante rebelión campesina en las provincias puneñas de Huancané y Azángaro. Rumi Maqui asistía a la Iglesia metodista episcopal de Huancayo en 1906 y, ocho años más tarde, el 27 de diciembre de 1914, fue recibido como miembro de la Iglesia metodista episcopal de Lima. El siguiente es el mensaje que Rumi Maqui pronunció en dicho acto:

Querido pastor, queridos hermanos:

Hace ocho años que asisto a las iglesias evangelistas habiendo sido la de Huancayo en 1906 la primera que concurrí, cuyo pastor era el reverendo Adolfo Vásquez. Mi asistencia a ella ha sido intermitente, a pesar mío, por razón de los empleos en que he desempeñado en algunos puntos de la república; y cuando el tiempo me lo ha permitido he procurado ser asiduo en mi concurrencia a las reuniones celebradas en este templo y en el Callao.

He pasado en verdad mucho tiempo para la determinación que adopto hoy de ingresar al seno de esta comunidad religiosa como 
miembro suyo; pero creo que el tiempo transcurrido, y el que le ha precedido en el curso de mi vida, en que he visto llegar al colmo el relajamiento, la inmoralidad y la vida licenciosa de los llamados ministros de Jesucristo, el pernicioso y corruptor ejemplo que dan a los pueblos, a quienes tanto daño hacen particularmente en el orden moral; en el tiempo transcurrido, repito, he podido establecer el contraste, y él no ha hecho sino llevar a mi ánimo el profundo convencimiento de la bondad, moralidad y pureza de la enseñanza en la Iglesia metodista de la verdadera doctrina de Jesucristo conforme al texto del gran libro de las más puras y sabias enseñanzas: la Biblia. Y penetrado hasta donde lo permite mi pequeña inteligencia que es aquí donde se alcanza a comprender el verdadero espíritu del cristianismo, donde se practican las puras doctrinas del Salvador, donde puedo uno expandir su espíritu en un ambiente de moralidad enseñada y difundida con ejemplo; penetrado repito de estas hermosas y halagadoras verdades y hecha puede decirse mi profesión de fe, no quiero que pase un día más sin ser, queridos hermanos, uno de los vuestros.

Y lo hago con el pleno convencimiento de que procedo ajustado a mi conciencia que está hecha, que está formada con el estudio, la observación y la experiencia de mucho tiempo. De hoy en adelante seré el grano de arena que entre en la edificación de nuestra Iglesia que ojalá abarque en no muy lejano tiempo los ámbitos del mundo y al ingresar gozoso a vuestro seno hago los más fervientes votos al Ser Supremo para que extienda su gracia a todos los que hoy viven sumidos en la más grosera superstición, en la ignorancia y en el oscurantismo, a fin de que abran sus ojos a la luz bienhechora, fecundante y civilizadora del Evangelio (El Mensajero, 1915).

Por otro lado, Julián Palacios, profesor adventista de la Escuela Normal de Varones, estableció una academia para la enseñanza del quechua y aimara para los estudiantes de dicha institución. Con estas medidas se notaba claramente el avance de la prédica cristiana que, además de centrarse en la evangelización, tenían otro mensaje de moralidad e igualdad, como lo manifiesta Fonseca (2005): «en estos años los evangelistas luchaban por la educación del indio, el sufragio político de la mujer, la práctica de la higiene y el combate del alcoholismo». Plegado a ese programa se produjo la conversión del sacerdote católico José de las Heras, que señaló el avance de la prédica anticlerical en el país y nos muestra una sociedad en proceso de cambio con las armas predispuestas para volver a entablar los debates sobre la libertad de cultos.

\section{La lucha por la libertad de cultos (1909-1913)}

En este periodo es importante resaltar dos hechos fundamentales: el primero, la presencia de los jesuitas en el Perú, y el segundo, los sucesos 
de Platería ocurridos en 1913. Como se había indicado anteriormente, después de 1872 los jesuitas tuvieron una presencia significativa en el país y contribuyeron con la Iglesia católica en la difusión del pensamiento cristiano.

Ante esta presencia, el doctor Christian Dam, fundador de la Liga de Librepensadores del Perú, publicó en 1909 un folleto titulado «Los jesuitas en el Perú», con un subtítulo que decía: «Memorial del Dr. Christian Dam al Congreso Nacional y Actas de las Provincias pidiendo el cumplimiento de la ley de noviembre de 1855, que ordena la expulsión de la Compañía de Jesús del territorio de la república».

El autor, dirigiéndose al Congreso, comienza diciendo:

Christian Dam [...] al amparo de la ley, ante vuestra excelencia con respeto y haciendo uso del derecho de petición que la Constitución me otorga, según el artículo 30 y en representación de numerosos ciudadanos de la república, como lo prueban las actas que acompaño, me presento y expongo. Luego de presentar algunos hechos, documentos y leyes que permiten hacer la historia de la expulsión de los jesuitas del territorio peruano, presento las actas firmadas por decenas de ciudadanos de las provincias del Perú, quienes, de 1907 a 1909, enviaban sus actas para publicarlas y gestionar ante los poderes políticos el cumplimiento de la ley de 1855. Publica la carta que envía el doctor Guillermo Seoane, fiscal de la Corte Suprema, al Poder Ejecutivo (28 de junio de 1907); acta de la provincia de Ascope (6 de octubre de 1907); actas del distrito de Pampas, capital de la provincia de Tayacaja (12 de octubre de 1907), actas del distrito de Huancané (12 de octubre de 1907); actas del distrito de Chavín, departamento de Áncash (20 de noviembre de 1907); actas de Junín (13 de diciembre de 1907); actas de Paita, departamento de Piura (21 de noviembre de 1907).

En estas actas se refleja claramente el pensamiento de los pobladores de las diversas provincias del interior del país en torno a la Compañía de Jesús, dando por descontado la no aceptación de la obra redentora y evangelizadora que esta compañía intentaba una vez más. Los liberales se oponen duramente a su prédica, por considerar que la difusión de su pensamiento es antisocial y atenta contra el progreso moral e intelectual de los individuos y familias del Perú.

A las denuncias de los liberales encabezados por Christian Dam, en contra de la Compañía de Jesús, hay que sumar también las denuncias que efectuaba la Asociación Proindígena. Ambas buscaban relatar, desde sus respectivas posiciones, el maltrato sufrido por los indígenas de parte de las autoridades de la Iglesia católica, todo lo cual reflejaba una tendencia anticlerical que pronto tendría como desencadenante la ley de la libertad 
de cultos. Al respecto, El Comercio de Lima recogió la denuncia efectuada por la Asociación Proindígena por los abusos del cura del distrito de Sicuani en el Cusco y publicó el decreto del subprefecto de Canchis en Sicuani:

Considerando:

Que habiéndose presentado en este despacho el indígena Pedro Machaca, acusando a don Bartolomé Ocopa Orué, de haberle arrebatado en su casa una vaca con su cría, después de maltratar a su esposa, negándose a devolverle la citada vaca; y resultando de las investigaciones que se han practicado en este despacho, con la complacencia de los interesados, de que, efectivamente, Ocopa Orué, cometió abuso expuesto por el demandante, bajo el pretexto de que como apoderado del cura Pacheco Castillo se hallaba autorizado a retener en su poder una prenda del indígena, mientras este pague la suma de 40 soles por derecho de entierro, que dice haberle debido el indicado Machaca, al cura, y que dichos 40 soles habían sido designados por la madre de Machaca, al tiempo de su muerte, con lo que quiso explicar el demandado que justificaba su actitud.

Que en este asunto el gobernador de Tinta, cuando se presentó en su despacho el demandante, desoyó la queja, dando por justificada la actitud de Orué.

Que siendo obligación de las autoridades velar por que no se siga cometiendo exacciones con los indígenas, bajo el pretexto de derechos eclesiásticos.

Se dispone:

Que, en lo sucesivo, los gobernadores de los distritos, cuando en sus respectivos despachos se presenten demandando los señores curas o sus apoderados, con quejas semejantes a la referida en la parte considerativa de este decreto, no podrán obligar, bajo ningún pretexto, ni por ninguna circunstancia, a los indígenas, más derechos eclesiásticos que los que el arancel vigente señale, para lo que cada despacho de las autoridades subalternas deberá tener en su archivo dicho arancel.

Los gobernadores, en sus respectivos distritos, vigilarán, bajo responsabilidad, de que los señores párrocos se limiten en sus cobros al arancel, denunciando en este despacho, cuando se extralimiten, para ocurrir en queja a las autoridades superiores.

Los gobernadores y sus subalternos, que en alguna forma autorizaran el que se cometan exacciones, cobrándose mayores derechos, serán penados con una multa al doble de la cantidad que dejaren cobrar sobre la tarifa señalada por el arancel.

Circúlese, ordenando que Ocopa Orué devuelva en el día la vaca y su cría, arrebatadas, imponiéndoles, por equidad, el arresto de 24 horas. Publíquese y trascríbase a quienes corresponda.

Regístrese.

Firma: Olazábal. Subprefecto (El Comercio, 11 de marzo de 1913). 
Como puede observarse, se materializaba desde diversos frentes una sola tendencia en contra de la postura de la Iglesia católica. De esta manera; si bien en el siglo pasado la prédica anticlerical fue llevada a cabo básicamente por el avance del pensamiento evangélico y liberal, a inicios del siglo XX existía un descontento general expresado desde otros sectores, como lo efectuado por Matto de Turner defendiendo la igualdad de la mujer y del indígena, o de los liberales que defendían la posición de Dam en torno al obrar de la Compañía de Jesús, o de la Asociación Proindígena, anclada en su defensa de los derechos de los indígenas.

Junto a esta labor evangelizadora proveniente de las más altas esferas eclesiásticas, se produjo un segundo hecho que precipitó la caída del régimen legal de intolerancia religiosa, el asalto a la misión adventista de Platería de Puno en 1913. El 3 de marzo de 1913, una numerosa turba organizada y liderada por el obispo de Puno, Valentín Ampuero, saqueó e incendió la misión e infringió brutales castigos físicos a los campesinos adventistas que pudo encontrar en su paso destructivo. Al respecto, El Comercio de Lima recogió de la revolución de Juli las impresiones de los labios de algunos indígenas con respecto a estos hechos:

Largo sería relatar todo lo que con ellos hablamos, y por hoy basta con que hagamos saber que es tal la transformación del indio que admira la constancia y empleo de energía que ha sabido gastar con largueza los misioneros de La Platería para convertir al indio de sucio, alcohólico, hipócrita, holgazán y salvaje, en ser dotado de un criterio más o menos sano, temperante, trabajador y de tan buenos sentimientos, que no podemos menos que enviarles a los señores Stahl y Hall, jefes de la misión, nuestras más sinceras felicitaciones y ofrecerles el modesto concurso de nuestro periódico en bien de la magna obra que se han propuesto y cuyos benéficos resultados hemos tenido ocasión de palpar personalmente, sintiendo solo no haber podido entrevistarnos con ellos para saludarlos, tomar mejores datos y apreciar de cerca los usos a que son destinados los amplios locales por ellos construidos para beneficiar a nuestra desgraciada raza aborigen, que más tarde será otra si los apóstoles como ellos continúan la gran obra emprendida con la fe de los que no dudan cuando ponen al servicio de la humanidad desvalida sus existencia y energías. Como es natural, la benéfica obra de los adventistas ha hecho perder entre los indígenas el ascendiente de los párrocos católicos. $\mathrm{Ha}$ bastado esto para que, como hace un año, el cura de Chucuito pretendiera lanzar a la indiada para incendiar los locales de la misión referida, lo que felizmente no pudo conseguir; y para que el obispo de Puno ahora se constituyera, como lo ha hecho el 4 del mes en curso, en La Platería, con 20 jinetes y amenace hostilmente a los misioneros, causándoles algunos daños a la propiedad. Como complemento de 
esta versión, informásemos que, por indicación del ilustrísimo obispo, el subprefecto del Cercado se constituyó en el lugar y apresó a los indígenas Camacho, Champi, Tarqui, Miranda, Naca, una mujer y un muchacho, a quienes llevó y arrestó en la cárcel.

Teniendo en consideración la gravedad de los sucesos y habiendo solicitado a los indígenas el amparo de la Asociación Proindígena, el secretario de esta institución telegrafió al delegado más cercano, que es el señor Remigio H. Franco, a fin de que investigue la verdad de los hechos, constituyéndose para el objeto en la citada parcialidad de La Platería (El Comercio, 26 de marzo de 1913).

En el mencionado asalto, el misionero adventista Fernando Stahl y el ilustrado indígena Manuel Zúñiga Camacho, fundador de la escuela, fueron los hombres más buscados por Ampuero para ser eliminados. La denuncia que las víctimas presentaron contra el obispo Ampuero fue increíblemente desestimada por el juez, por la Corte Suprema de Justicia y por la Cámara de Diputados. Pero los sucesos de Platería habían estimulado un acto que sería trascendental para la causa de la tolerancia religiosa en el Perú: el 25 de agosto de 1913 el senador por Puno Severiano Bezada proponía que se eliminara del artículo cuarto de la Constitución de 1860 la frase «y no permite el ejercicio público de otra alguna».

El texto de tal histórica iniciativa decía así:

Cámara de Senadores:

El senador que suscribe, teniendo en consideración que las leyes deben conformarse al espíritu que corresponde a la época en la cual han de regir, propone se reforme la parte terminal de dicho artículo, que dice: «y no permite el ejercicio público de otra alguna», de manera que el referido artículo quedará así: «Artículo 4. La nación profesa la religión católica, apostólica y romana, el Estado la protege» ( $L a$ Prensa, 25 de agosto de 1913).

La iniciativa fue derivada para su análisis a la Comisión de Constitución, presidida por el doctor Mariano Cornejo. Posteriormente, el proyecto fue remitido a la Comisión de Culto Público y el 3 de octubre de 1913 se dio inicio al debate del proyecto de libertad de cultos. Ante ello, la primera en reaccionar fue la prensa clerical, que alegaba que este ataque satánico hundiría al Perú en una anarquía que la llevaría a la ruina total, que se relajaría la moral y se degradaría la cultura, y la verdadera religión desaparecería.

\section{La promulgación de la libertad de cultos (1915)}

En 1915, el Perú se encontraba en una situación anacrónica y desventajosa con respecto a las demás repúblicas americanas en lo referente a la libertad de cultos. Las Constituciones políticas del Brasil, Cuba y Estados 
Unidos ya habían establecido la separación entre el Estado y las Iglesias. La República peruana era la única que conservaba una ley inquisitorial que prohibía a sus ciudadanos y extranjeros adorar a Dios, según sus luces y conciencia. El Perú era el único país en el mundo civilizado que no había adoptado la tolerancia religiosa, ya que el único otro país en el mundo que no había abrazado esta ley era el Tíbet.

Como podemos observar a continuación, las Constituciones de otros países ya se habían a acogido a la ley:

Argentina: la Constitución de la confederación argentina dice:

Artículo 2. El gobierno federal sostiene el culto católico, apostólico, romano.

Artículo 20. Declara que los extranjeros pueden [...] ejercer libremente su culto.

Brasil: la Constitución de la República de los Estados Unidos del Brasil, de febrero de 1891, dice:

Artículo 72. Párrafo 3. Todos los individuos y confesiones religiosas pueden ejercer pública y libremente su culto, asociándose para ese fin y adquiriendo bienes con tal que observen las disposiciones del derecho común.

El Salvador: la Constitución de El Salvador, de 1886, dice:

Artículo 12. Se garantiza el libre ejercicio de todas las religiones, sin más límite que el trazado por la moral y el orden público.

Estados Unidos de Norteamérica: la Constitución de Estados Unidos dice:

El Congreso no dará ninguna ley relacionada con el estable cimiento de religión alguna, o que prohíba el libre ejercicio de ella o que restrinja la libertad de la palabra o de la prensa.

México: la Constitución de los Estados Unidos de México, promulgada en 1857, dice:

Artículo 6. La manifestación de las ideas no puede ser objeto de ninguna inquisición judicial o administrativa, sino en el caso de que ataque la moral, los derechos de tercero, provoque algún crimen o delito, o perturbe el orden público (El Comercio, octubre de 1913).

Como puede observarse, el pensamiento en torno a la libertad de cultos era común en todas las repúblicas y se permitía su celebración. En el Perú, este debate, iniciado en octubre de 1913, tuvo serios enfrentamientos entre los diputados, el clero, los liberales y grupos femeninos anclados en diversos sectores. Así, por ejemplo, uno de los grupos más numerosos que protestaba en contra de su promulgación fue el compuesto por las señoras de la Unión Católica, lideradas por la madre, hija política y hermanas del jefe de Estado, señor Pardo, y las esposas de los ministros del 
gabinete, quienes dirigieron un memorial al presidente, el 23 de octubre, bajo los siguientes términos:

La Unión Católica de Señoras, y con ella todas las señoras de Lima, nos presentamos ante vuestra excelencia para protestar enérgicamente del ultraje hecho a nuestra religión, a la Santa Sede, al Episcopado y clero nacional, hiriendo el sentimiento católico de la inmensa mayoría del país, en el santuario mismo de las leyes, por los que están encargados de interpretar la voluntad de los pueblos que representan y cuyo mandato han traicionado, alterando violenta y sorpresivamente el artículo 4 de la Constitución del Estado, en la sesión de la honorable Cámara de Diputados, del día 20 de presente.

No hay ninguna razón, excelentísimo señor, que justifique este atropello. La libertad de cultos, que puede ser necesaria en los países donde es un hecho la diversidad de ellos, no existe en el Perú donde la religión católica es la única que profesan los peruanos que tienen alguna religión, ni puede tampoco ser un progreso para un país que tiene la felicidad de conservar la fe católica, porque el progreso solo es tal si lleva a la verdad, y la verdad está solo en la religión católica y negar este principio equivale a una apostasía de nuestra fe.

Y no solo el bien de la Iglesia, excelentísimo señor, y el sentimiento nacional están interesados en impedir la consumación de esta atentado; hay también un interés de patriotismo, un daño inmenso que evitar, impidiendo que se rompa el único lazo de unidad que hasta ahora que hasta ahora se había mantenido intacto en medio de las discordias que debilitan la vida nacional y que ahora penetrarían hasta el santuario del hogar, pues a nadie se oculta que esta pretendida reforma de la Constitución, por lo mismo que no viene a remediar una verdadera necesidad pública, solo ha nacido del propósito de hostilizar a la Santa Iglesia y favorecer la propaganda de sectas, que, con su contradictoria multiplicidad de ideas y cultos, traen al país un nuevo y más profundo elemento de anarquía y disolución social.

Confiamos, excelentísimo señor, en los tradicionales sentimientos de vuestra excelencia, en su respeto por los principios fundamentales de nuestra Constitución y en la gravísima importancia de la causa que defendemos, suplicamos a vuestra excelencia que, haciendo uso de las facultades que la ley le otorga, se digne observar la que ha sido aprobada por la honorable Cámara de Diputados, mutilando el artículo 4 de la Constitución, a fin de que no pase a ser ley del Estado. Es justicia, etc.

Lima, 23 de octubre de 1915.

Isabel del Valle y Osma, presidenta

Manuela M. de Araníbar, primera vicepresidenta

Rosa P. de Gonzales Orbegoso, segunda vicepresidenta

Consuelo Astete, tesorera [...] 
El Cabildo Abierto de Lima también protestó por la pronta promulgación de la ley. Dirigió una resolución al ilustrísimo señor arzobispo de Lima, monseñor don Pedro Manuel García Naranjo, en términos parecidos a las señoras de la Unión Católica, e indicó que lo único que generaría la promulgación de la ley sería la «división en la familia peruana en las circunstancias más difíciles por las que atraviesa la república». Sin embargo, a pesar de todas estas protestas, la Ley de Tolerancia de Cultos se aprobó el 11 de noviembre de 1915.

\section{Conclusiones}

En la larga lucha por conseguir la ley de la libertad de cultos, resaltan varios momentos en los que se desencadenan pugnas internas entre diversos sectores de la sociedad, en un primer momento, después de la independencia, amparados en la enseñanza lancasteriana, los predicadores evangélicos introdujeron por primera vez la enseñanza protestante, materializando una prédica de igualdad y unidad en torno a la obra salvífica llevada a cabo por Jesucristo para la salvación de las almas. A esta prédica se unió el colportaje, mediante la difusión y venta de biblias.

Desde mediados del siglo XIX se sintieron con mayor fuerza las pugnas entre la Iglesia católica y el avance de la obra evangélica. En un primer momento destacó la prédica liberal en torno a la tolerancia religiosa y luego la obra llevada a cabo por Penzotti, con quien se fundó la Iglesia metodista y se avanzó en la igualdad de matrimonios, que sin embargo tuvo una dura reacción por parte de la Iglesia católica mediante la publicación de El Amigo del Clero.

En la primera década del siglo XX existió una clara tendencia anticlerical manifestada en diversas posiciones, como el rechazo a la Compañía de Jesús por parte de la Sociedad de Librepensadores, las continuas denuncias en contra del abuso de los curas por la Asociación Proindígena o los sucesos de Platería, que fueron los indicadores de que el campo para la promulgación de la libertad de cultos había llegado. En este momento se presentó la ley ante el Congreso de la República y en 1913 se amparó la libertad de cultos. No obstante, las pugnas no habían terminado y apenas se iniciaba un camino distinto. 


\section{REFERENCIAS BIBLIOGRÁFICAS}

Alomía, M. (1998). Un importante centenario en la historia de las misiones. Theologika, vol. XIII, nro. 2.

Amat, O. y Pérez, L. (2007). Presencia evangélica en la sociedad peruana. Lima: Instituto para la Misión Transformadora.

Armas, F. (1998). Liberales, protestantes y masones. Modernidad y tolerancia religiosa. Perú, siglo XIX. Lima: Fondo Editorial de la Pontificia Universidad Católica del Perú y Centro de Estudios Regionales Andinos Bartolomé de las Casas.

Berger, P. (1981). Para una teoría sociológica de la religión. Barcelona: Editorial Kairós.

Canclini, A. (1998). Diego Thomson. Apóstol de la enseñanza y distribución de la Biblia en América Latina y España. S. d.

Durkheim, É. (1968). Las formas elementales de la vida religiosa. Buenos Aires: Schapire.

El Amigo del Clero (1900-1913).

El Comercio (octubre de 1907-octubre-noviembre de 1915).

El Mensajero (1915). Año 1, nro. 2, enero de 1915.

Escobar, S. (julio-diciembre de 1996). El proceso judicial contra Francisco Penzotti (1890-1891). Época. Archivo Histórico del Protestantismo, año 2, nro. 3 .

Fonseca, J. (2002). Misioneros y civilizadores. Protestantismo y modernización en el Perú (1915-1930). Lima: Fondo Editorial de la Pontificia Universidad Católica del Perú.

Gutiérrez, T. (Comp.). (1996). Protestantismo y política en América Latina y el Caribe. Entre la sociedad civil y el Estado. Lima: Comisión para el Estudio de la Historia de las Iglesias en América Latina y el Caribe.

Klaiber, J. (1980). Religión y revolución en el Perú. 1824-1976. Lima: Universidad del Pacífico.

(1988). La Iglesia en el Perú. Lima: Fondo Editorial de la Pontificia Universidad Católica del Perú.

LaPrensa (noviembre de 1913).

Marzal, M. (1988). Los caminos religiosos de los inmigrantes en la gran Lima. Lima: Fondo Editorial de la Pontificia Universidad Católica del Perú. 
Ramos, C. (2006). Historia del derecho civil peruano. Siglos XIX y XX. Tomo V, Los signos del cambio, vol. 2, Las instituciones. Lima: Fondo Editorial de la Pontificia Universidad Católica del Perú.

Recepción: 27/1/2018

Aceptación: 16/3/2018 